ORIGINAL ARTICLE

\title{
Physicians' Knowledge and Attitude towards Mental Health in Saudi Arabia
}

\author{
Abdulrahman A. Al-Atram ${ }^{1 *}$
}

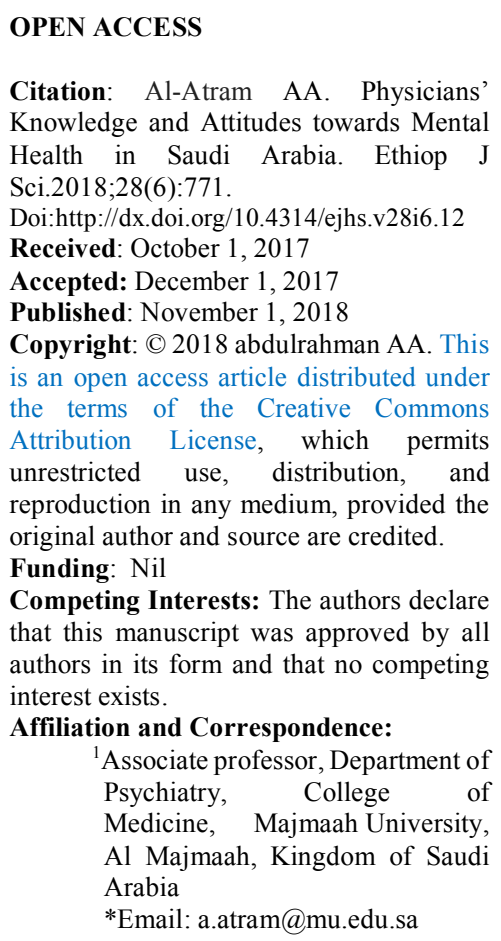

\section{ABSTRACT}

BACKGROUND: Physicians working in Saudi Arabia belong to different countries and may have differences in knowledge and attitude towards psychiatry. We evaluated non-psychiatric physician's knowledge and attitude towards psychiatric disorders, such as anxiety and depression, in the Kingdom of Saudi Arabia.

METHODS: $A$ descriptive cross-sectional study design was used. The current knowledge and attitude towards anxiety and depression of physicians were determined by using a questionnaire. We distributed 180 study questionnaires at various hospitals to be answered by physicians in the Riyadh Province of Saudi Arabia. One hundred and forty-two completed questionnaires were included in the study. The participants were divided into three groups: (1) 63(44.4\%) general practitioners (GPs), (2) 55 (38.7\%) specialists and (3) 24 (16.9\%) family practitioners. Data were analysed using the chi-square, ANOVA and independent sample t-test.

RESULTS: GPS and specialists showed a negative attitude towards psychiatric patients, but family practitioners showed a positive attitude. There were statistically significant differences $(p<0.05)$ in the knowledge regarding anxiety and depression among the groups. The relationship between specialty and knowledge was statistically significant $(p<0.05)$ and the effect of first language is insignificant $(p>0.05)$.

CONCLUSION: Expansive enlightenment programmes, continued medical education and inclusion of psychiatric posting in rotating residential internship programme during undergraduate courses are required for physicians not only to fill the gap in knowledge and attitude but also to improve their cognitive, communication and interpersonal skills.

KEYWORDS: GPS, family doctors specialist, survey, mental health, anxiety, depression, knowledge and attitude.

\section{INTRODUCTION}

In Saudi Arabia, the Ministry of Health (MOH) is the major government agency entrusted with providing preventive, curative and rehabilitative healthcare for the population of Saudi Arabia. The $\mathrm{MOH}$ with its chain of primary health care $(\mathrm{PHC})$ centres provides medical care to the citizens and 
residents of the Kingdom. The total number of PHC centres has increased from 1925 in 2007 to 2259 by 2012 . The highest growth in number of PHC centres were in Makkah (23\%) and Riyadh (20\%). In the year 2012, physicians in $\mathrm{MOH}$ hospitals included 3201 General Practitioners (GP's), 2079 Internal Medicine, 399 Urology, 217 Chest diseases, 313 Skin and Venereology, 1083 Anesthesia, 2466 Pediatrics, 5075 Psychiatry and 766 Family Medicine experts. The surgeons included 2466 General Surgery, 1552 Dentists, 817 Orthopedics, 110 Cardiothorasic Surgery, 225 Neuro Surgery, 140 Plastic Surgery, 479 ENT, 67 Ophthalmology, 1790 OBS/GYN, 503 Cardiology adding to a total of 26,266 including other specialists (1). There are $435 \mathrm{PHC}$ centres in the study area of Riyadh province with an estimated population of 7739570 (2). The other government bodies include referral hospitals, security forces medical services, army forces medical services, national guard health affairs, ministry of higher education hospitals (Teaching hospitals), ARAMCO hospitals, royal commission for Jubail and Yanbu health services, school health units of ministry of education and the red crescent society. The private sector also contributes to the delivery of healthcare services especially in cities and large towns with a total of 125 hospitals and 2218 dispensaries and clinics (3).

In accordance with the Saudi Constitution, the government provides all citizens and expatriates working within the public sector with full and free access to all the public health services. The primary function of $\mathrm{PHC}$ centres is to provide primary care services, both preventive and curative, referring cases that require more advanced care to public hospitals (the secondary level of care) while cases that need more complex level of care are transferred to central or specialized hospitals (the tertiary level of health care). The World Health Organization (WHO) recommend all countries to make PHC centres the point of first contact for those with mental disorders. In situations where PHC physicians cannot handle these patients, recommendation was to refer to psychiatrists in general hospital (secondary level) and if psychiatrists in those settings could not manage patients then they were referred to specialty psychiatric hospitals or teaching hospitals (tertiary level). There were over 700 psychiatrist (3.0 per $1,00,000)$ including 380 who performed primarily outpatient psychiatry and 263 who worked in mental hospital.1980 psychiatric nurses working in outpatient facilities and 1176 in mental hospitals. There were also 515 psychologist, social workers and occupational therapist at outpatient facilities and 611 working in mental hospitals (4).

The prevalence of mental health disorders is high and people can be affected irrespective of age, culture or socioeconomic status (5). Often in general health facilities, once patients are examined by physicians; they are then infrequently referred to psychiatrists or other mental health professionals. One reason for this behaviour is that patients are often more comfortable with physicians because they do not want to be stigmatised by others for visiting a psychiatrist. Hence, general practitioners (GPs) and specialists have a pivotal role in the management of psychiatric patients (6).

In Saudi Arabia, the majority of physicians are from other countries. Most of the GPs or physicians working in Saudi Arabia came from other Arab countries (North Africa and Middle East) and from the Indian subcontinent (India, Pakistan and Bangladesh). Anxiety and depression are the most common mental disorders and are not easy to diagnose in primary care because of complex barriers. These barriers are usually classified as the patient, physician and health system or organisational factors (7-9). The patients may consider the symptoms as non-medical in nature and think that the physician cannot help. He or she thinks the problem is simple and can be handled by the person while bearing in mind the stigma of mental illness. Physician factors include negative attitude towards mental illness, lack of knowledge to differentiate the common symptoms of anxiety and depression from other mental disorders, lack of good communication and interviewing skills, medicalization of symptoms and fear of offending the patient. This situation is complicated by comorbidity with a medical condition and negative or false perception about 
the treatment, in addition to personal factors, such as discomfort in dealing with emotional and interpersonal issues. Health system or organisational barriers include limitations on third party coverage, limited treatment resource availability, restriction on access to a particular treatment and fragmentation of care, limited time for history taking and counselling or education and poor reimbursement for antidepressants and counselling $(9,10)$. Other barriers to effective care include lack of resources, lack of trained health providers and social stigma associated with mental disorders (11).

Hence, this study was designed to assess the physicians' knowledge and attitude towards anxiety and depression disorder in Saudi Arabia. Our goal is to use the data to help make decisions regarding updating the knowledge of physicians so that they will be able to diagnose anxiety and depression effectively and refer patients to psychiatrists for further treatment.

\section{MATERIALS AND METHODS}

Study design: This was a descriptive crosssectional study. This study was conducted to assess physicians' knowledge and attitude towards anxiety and depression.

Study setting and period: The study was conducted during the period of November 2016 to April 2017. The physicians including general practitioners (GPs), specialists and family medicine practitioners working in various hospitals of Ministry of Health in the Riyadh Province of Saudi Arabia were invited telephonically and by electronic mail to participate.

Study participants: Copies of the questionnaire were sent by mail to 180 physicians, who were requested to complete the questionnaire and return it to the researcher. A total of 142 completed questionnaires were received (79\%) and included in the study. The GPs group consisted of 63 participants, the specialist group consisted of 55 participants, and the family practitioner group consisted of 24 participants.

Measurements: The study questionnaire was designed to assess physicians' knowledge and attitude towards anxiety and depression. The questionnaire had three parts: demographic data, such as age, sex, specialty and language; attitude and interest in psychiatry and assessment of knowledge about anxiety and depression and management issues. With each item for attitude were rated on a Likert's scale of four points ranging from strongly agree to strongly disagree. The knowledge questions consisted of 20 items: 10 for anxiety and 10 for depression. The questions were a simpler form of some questions available online from the Membership of the Royal College of Psychiatry Parts I and II. Another seven were formulated by the researcher after gaining knowledge on the subject from the literature review and semi-structured interviews with physicians and approved by a panel of physicians, psychiatrists and statistician $(12,13)$.

Statistical analysis: The data were analysed to generate descriptive statistics using SPSS software version 21. Chi-square was performed to compare the observed values with the standards and ANOVA helped in analysing variance with level of significance as $\mathrm{p}$ value less than 0.05 . Independent sample $t$ test was used to compare the knowledge on anxiety and depression among the Arabic and non-Arabic speaking groups with level of significance as $\mathrm{P}$ value less than 0.05 .

Ethical approval: This study was approved by the ethics of research committee of Majmaah University. The participants were sent a consent form, the study details and rights of the participants along with the questionnaires. The participation was voluntary and the signed consent form was obtained. The participants were assured of confidentiality of the data. This study is a selfsupported study and no internal or external funding is availed.

\section{RESULTS}

Background characteristics: Out of 180 questionnaires, over a period of six months, 142 completed questionnaires were received. The participants were divided into three groups: the GPs group consisted of 63 participants, the specialist group consisted of 55 participants and the family practitioner group consisted of 24 participants. The age range of most of the GPs $(44.4 \%)$ and specialists $(63.6 \%)$ was $36-45$ years. Most family practitioners (54.2\%) were 25-35

DOI: http://dx.doi.org/10.4314/ejhs.v28i6.12 
years of age. Most of the participants in all groups were males. Arabic speakers comprised $77.8 \%$ of the GPs, $76.4 \%$ of the specialists and $100 \%$ of the family practitioners (Table 1). Among the three groups, $70.8 \%$ of family practitioners referred more than five cases per year to a psychiatrist, followed by specialists and GPs. The data showed that $46.3 \%$ of the GPs referred less than five cases per year to psychiatrists followed by $23.64 \%$ of the specialists and $20.8 \%$ of the family practitioners. Among all participants, $42.9 \%$ of the GPs, $12.7 \%$ of the specialists and $8.3 \%$ of the family practitioners reported that they had never referred any case to a psychiatrist. Importantly, $77.9 \%$ of the GPs and $94.6 \%$ of the specialists reported that they had no interest in psychiatry, but $91.67 \%$ of the family practitioners showed an interest in psychiatry. Evaluation of the attitude items showed that more than half of the GPs and specialists agreed with more than five of the items that reflected a negative attitude towards psychiatric patients, but family practitioners showed a positive attitude.

Table 1: Demographic data: Participants of the study

\begin{tabular}{cccc}
\hline group & General practitioner(63) & Specialist (55) & $\begin{array}{c}\text { Family medicine } \\
\text { practitioners (24) }\end{array}$ \\
\hline Age 25-35 & 20 & 7 & 13 \\
$36-45$ & 28 & 35 & 9 \\
$46-55$ & 15 & 13 & 2 \\
Gender Male & 43 & 48 & 15 \\
Female & 20 & 7 & 9 \\
Language Arabic & 49 & 42 & 24 \\
Non Arabic & 14 & 13 & 0 \\
Specialty & 63 & 55 & 24 \\
\hline
\end{tabular}

Knowledge about anxiety: When all of the groups were assessed for their knowledge of anxiety, we found that $36.5 \%$ of the GPs, $63.6 \%$ of the specialists, and $95.8 \%$ of the family practitioners were able to identify the type of anxiety. Most of the participants were able to correctly identify key features of anxiety. The GPs (77.8\%) and family practitioners $(54.2 \%)$ were more accurate in describing obsessive-compulsive disorders than were specialists $(16.4 \%)$. The specialists $(61.8 \%)$ and family practitioners $(100 \%)$ were more accurate than were GPs $(46.0 \%)$ in identifying the key features of a history of phobia in patients. Almost half (49.1\%) of the specialists, $62.5 \%$ of the family practitioners and $38.1 \%$ of the GPs were able to identify the clinical symptoms of panic attacks. Regarding post-traumatic stress disorders, family practitioners $(91.7 \%)$ were more accurate than were specialists $(38.2 \%)$ and GPs $(55.6 \%)$. GPs $(60.3 \%)$ were more accurate in identifying the causes of hallucinations compared with the family practitioners $(45.8 \%)$ and specialists $(12.7 \%)$. Less than half of the GPs (36.5\%) and specialists $(38.2 \%)$ were accurate in describing the characteristics of phobias followed by $70.8 \%$ of the family practitioners. A total of $57.1 \%$ of GPs, $61.8 \%$ of specialists and $33.3 \%$ of the family practitioners were able to identify the organic causes of anxiety. Almost half of the GPs (55.6\%) and $75.0 \%$ of the family practitioners were able to identify the correct presentation of obsessivecompulsive disorder followed by $25.5 \%$ of the specialists (Table 2).

Knowledge about depression: Responses to the depression questions showed that $65.1 \%$ of the GPs, $74.5 \%$ of the specialists and $58.3 \%$ of the family practitioners were aware of depression symptoms. Family practitioners were more accurate in the differentiation of mild, moderate and severe depression. Only $22.2 \%$ of the GPs, $27.3 \%$ of the specialists and $75.0 \%$ of the family practitioners responded correctly on the relationship between depression and other diseases and medications. All three groups of participants

DOI: http://dx.doi.org/10.4314/ejhs.v28i6.12 
were less accurate in recognising depression in the elderly. Postpartum depression was accurately recognised by $23.8 \%$ of the GPs, $49.1 \%$ of the specialists and $58.3 \%$ of the family practitioners. Family practitioners $(79.2 \%)$ were more accurate than GPs $(44.4 \%)$ and specialists $(45.5 \%)$ in recognising the relationships between visual hallucinations and other psychotic disorders. Family practitioners $(83.3 \%)$ were more accurate in determining the relationships between suicide attempts and other factors in depression than were
Specialists $(63.6 \%)$ and GPs $(57.1 \%)$. Specialists $(61.8 \%)$ responded accurately on the topic of drug interactions. Only $38.1 \%$ of the GPs, $25.5 \%$ of the specialists and $16.7 \%$ of the family medicine specialists were aware of the features enabling discrimination between major depression and primary anorexia nervosa. Family practitioners were more accurate in identifying drug interactions that can occur during treatment of psychiatric patients (Table 2).

Table 2: Responses of participants (\%) indicating knowledge about anxiety and depression. Pearson chisquare and df used to evaluate difference in knowledge about anxiety and depression among three groups.

\begin{tabular}{|c|c|c|c|c|}
\hline \multirow[t]{2}{*}{ Question } & $\begin{array}{l}\text { General } \\
\text { practitioner }\end{array}$ & Specialist & $\begin{array}{l}\text { Family } \\
\text { Practitioner }\end{array}$ & \multirow[t]{2}{*}{$\begin{array}{l}\mathrm{p}- \\
\text { value }\end{array}$} \\
\hline & Correct & Correct & Correct & \\
\hline 18. The following are forms of anxiety except: & 36.5 & 63.6 & 95.8 & 0.000 \\
\hline 19. Key features of generalised anxiety disorder include: & 82.5 & 76.4 & 100 & 0.036 \\
\hline 20. Obsessive compulsive disorder is best described as: & 77.8 & 16.4 & 54.2 & 0.000 \\
\hline $\begin{array}{l}\text { 21. Which feature of the history is of particular importance in } \\
\text { phobia patients: }\end{array}$ & 46 & 61.8 & 100 & 0.000 \\
\hline $\begin{array}{l}\text { 22. A } 20 \text { year female college student presents with recurrent } \\
\text { attacks of sweating, chest pain and palpitations. Her blood } \\
\text { investigations, E.C.G and clinical examination are normal. She } \\
\text { is probably suffering from: }\end{array}$ & 38.1 & 49.1 & 62.5 & 0.110 \\
\hline 23. Features of Post-traumatic Stress Disorder include: & 55.6 & 38.2 & 91.7 & 0.000 \\
\hline 24 Hallucinations may be caused by: & 60.3 & 12.7 & 45.8 & 0.000 \\
\hline 25. Which of the following is not true of phobias: & 36.5 & 38.2 & 70.8 & 0.010 \\
\hline 26. Organic causes of anxiety include: & 57.1 & 61.8 & 33.3 & 0.058 \\
\hline $\begin{array}{l}\text { 27. The following may present as obsessions in obsessive } \\
\text { compulsive disorder: }\end{array}$ & 55.6 & 25.5 & 75 & 0.000 \\
\hline 28. Which of the following is not a symptom of depression: & 65.1 & 74.5 & 58.3 & 0.311 \\
\hline $\begin{array}{l}\text { 29. A } 45 \text { year diabetic, father of five suffers from low self- } \\
\text { esteem, poor sleep, sadness and poor concentration now and } \\
\text { then. He is probably suffering from: }\end{array}$ & 12.7 & 25.5 & 58.3 & 0.000 \\
\hline 30. Which of the following statements is true about depression: & 22.2 & 27.3 & 75 & 0.000 \\
\hline $\begin{array}{l}\text { 31. Which statement is not true about depression in elderly } \\
\text { patients: }\end{array}$ & 17. & 38.2 & 87.5 & 0.000 \\
\hline 32. Regarding postpartum depression: & 23.8 & 49.1 & 58.3 & 0.002 \\
\hline 33. Visual hallucinations in the elderly are common in: & 44.4 & 45.5 & 79.2 & 0.009 \\
\hline 34. Suicide attempts in depression are more likely if there is: & 57.1 & 63.6 & 83.3 & 0.075 \\
\hline $\begin{array}{l}\text { 35. Common side effects of tricyclic antidepressants include } \\
\text { all except: }\end{array}$ & 33.3 & 61.8 & 20.8 & 0.001 \\
\hline $\begin{array}{l}\text { 36. The following are good discriminating features between } \\
\text { major depression and primary anorexia nervosa: }\end{array}$ & 38.1 & 25.5 & 16.7 & 0.102 \\
\hline 37. Drugs which interact significantly with tricyclics include: & 19 & 23.6 & 54.2 & 0.003 \\
\hline
\end{tabular}

Comparison between groups for anxiety and depression: The differences in knowledge about anxiety and depression were found to be statistically significant $(p<0.05)$ among the groups,

DOI: http://dx.doi.org/10.4314/ejhs.v28i6.12 
and both the GPs and specialists in the study population had statistically significant less knowledge than did family practitioners $(p<0.05)$ (Table 2, Table 3). There was statistically nonsignificant difference in knowledge of anxiety and depression among Arabic and non-Arabic participants (Table 4).
Table 3: ANOVA statistical analysis results for differences in knowledge of depression and anxiety among the three groups.

\begin{tabular}{lllll}
\hline & $\begin{array}{l}\text { Sum of } \\
\text { Squares }\end{array}$ & $\begin{array}{l}\text { Mean } \\
\text { Square }\end{array}$ & F & Sig. \\
\hline $\begin{array}{l}\text { Between } \\
\text { Groups }\end{array}$ & 394.035 & 197.018 & 36.857 & .000 \\
Within & 743.014 & 5.345 & & \\
$\begin{array}{l}\text { Groups } \\
\text { Total }\end{array}$ & 1137.049 & & \\
\hline $\begin{array}{l}\text { df= degrees of freedom, } p<0.05 \text { is significant, } \\
\text { Sig.=significance }\end{array}$
\end{tabular}

Table 4: Student's t test and df used to evaluate knowledge of anxiety and depression among Arabic and non-Arabic groups

\begin{tabular}{lllllll}
\hline Group & No. & Mean & SD & t & df & $\begin{array}{l}\text { P } \\
\text { value }\end{array}$ \\
\hline Arab general practitioners vs non- arab general & 49 & 8.959 & 2.20756 & 1.008 & 61 & 0.318 \\
practitioners & 14 & 8.286 & 2.19890 & & & \\
Arab specialists vs non- arab specialists & 42 & 9.0238 & 2.39398 & .632 & 53 & 0.530 \\
& 13 & 8.5385 & 2.50384 & & & \\
Overall Arab vs non-arab participants & 91 & 8.9890 & 2.28276 & 1.160 & 116 & 0.249 \\
& 27 & 8.4074 & 2.30817 & & & \\
\hline
\end{tabular}

$\mathrm{df}=$ degree of freedom, $\mathrm{p}<0.05$ is significant

\section{DISCUSSION}

The response rate of the study questionnaire was 79\% (20 GPs, 15 specialists and 3 family practitioners did not responded). A total of 142 completed questionnaires were included in the study. Among the respondents, the highest number was $63(44 \%)$ for the GPs followed by $55(39 \%)$ for the specialists and $24(17 \%)$ for the family practitioners. The results of the attitude items showed that a large number of participants in GPs and specialist group agreed with more than five of the items that indicated a negative attitude towards psychological problems. Our results are in agreement with those of previous studies in which physicians had negative attitudes towards psychiatry and psychiatric patients (14-18), but family practitioners showed positive attitude which is in agreement with a study done in Abu Dhabi (12).

Another part of the questionnaire consisted of 20 knowledge questions, including 10 on anxiety and 10 on depression, and more than $50 \%$ of the
GPs correctly answered six questions. When the responses of specialists were analysed for anxiety, it was found that five of the ten questions were answered correctly by the specialists. The family physicians were most accurate in their responses. The answers to eight of the ten questions were correct for more than $50 \%$ of the family physicians (Table 2).

The differences in the percentages of the participants for the correct and incorrect responses were statistically significant $(p<0.05)$ (Tables 2 and 3). Our results, which indicate more knowledge about anxiety and depression by family practitioners, are consistent with those of previous studies (19-20) and contradictory with the study from Australia in which GPs gave a higher percentage of correct answers about knowledge of anxiety and depression (13).

The knowledge questions about depression revealed that more than half $(80 \%)$ of the questions were answered incorrectly by $50 \%$ or more of the GPs. Specialists were slightly better than GPs;

DOI: http://dx.doi.org/10.4314/ejhs.v28i6.12 
more than $50 \%$ of the specialists responded correctly. Family physicians were better than both specialists and GPs as indicated by the fact that only three questions received low percentages of correct answers (Table 2).

The differences in the percentages of participants who gave incorrect responses were statistically significant for both GPs and specialists (Tables 2,3). These results are in agreement with those of previous studies $(21,22)$. The lack of adequate knowledge results in the wrong diagnosis of psychiatric disorders. A probable explanation of why family practitioners had good knowledge about anxiety and depression could be that their training curriculum includes effective psychiatry training by psychiatrist. Our study also reveals non-significant difference among Arabic and nonArabic participants (Table 4); this is in agreement with a similar study conducted in Abu Dhabi (12).

In conclusion, family physicians had a better knowledge and positive attitude to recognise and treat anxiety and depression than GPs and specialists. Therefore, it is evident that the effective psychiatric training received by the family physicians could have resulted in better diagnostic skills. This finding suggests the possibility of a larger number of patients screened by the GPs, and specialists may not be adequately recognised and may not receive appropriate referrals and treatments. On the basis of our findings, we recommend that more training courses, enlightenment programmes, continued medical education and inclusion of sufficient psychiatric postings in rotating internships during undergraduate course work to increase the knowledge about anxiety and depression for physicians for a holistic health care.

\section{REFERENCES}

1. Health Indicators. Ministry of Health, Department of Statistics. 2006. https://www.moh.gov.sa/en/Ministry/Statistic s/Book/Pages/default.aspx

2. General authority for statistics, Kindom of Saudi Arabia, Statistixcal year book of 2015; Issue Number 51. Available from; https://www.stats.gov.sa/en/411.
3. M.Almalki,G.Fitz Gerald, M. Clark. Health care system in Saudi Arabia: An Overview. Eastern Mediterranean Health Journal, 2011;10:784-93.

4. Koenig, H.G., et al. Mental Health Care in Saudi Arabia: Past, Present and Future. Open Journal of Psychiatry, 2014;4: 113-130.

5. Baumeister H, Harter M. Prevalence of mental disorders based on general population surveys. Soc Psychiatry Psychiatr Epidemiol, 2007; 42:537-46.

6. Ndetei DM, Khasakhala, Mutiso V, Mbwayo. Knowledge, attitude and practice (KAP) of mental illness among staff in general medical facilities in Kenya: Practice and policy Implications. Afr J Psychiatry, 2011;14:225.

7. Goldman LS. Psychiatry in primary care: possible roles for organized medicine. Psychiatry Ann, 1997; 27:42-59.

8. Preboth M. Clinical review of recent findings on the awareness, diagnosis and treatment of depression. Am Fam Physician, 2000; 61:3158-68.

9. Ellen SR, Norman TR, Burrows GD. Assessing anxiety and depression in primary care. Med J Aust, 1998;167:328-33.

10. Richards JC, Ryan P, McCabe MP, et al. Barriers to the effective management of depression in general practice. Aust $N J$ Psychiatry, 2004; 38:795-803.

11. World Health Organization. Depression. Media Centre fact sheet no. 369. Geneva, Switzerland: WHO; October 2012. www.who. int/mediacentre/factsheets/fs369/en/ index.

12. Saeed M, McCall L. General Practitioners knowledge and attitude towards anxiety and depression in Abu Dhabi. Middle East Journal of Family Medicine, 2006;4:3-9.

13. McCall L, Clarke DM, Rowley G. A questionnaire to measure general practitioners' attitudes to their role in the management of patients with depression and anxiety. Aust Fam Physician, 2002; 31:299-303.

14. Ohtsuki T, Kodaka M, Sakai R, Ishikura F, Watanabe Y, Mann A, et al. Attitudes toward depression among Japanese non-psychiatric medical doctors: A cross-sectional study. $B M C$ Research Notes, 2012; 5:441. 
15. Aghukwa NC. Attitude of health workers in the care of psychiatric patients. Ann Gen Psychiatry, 2009; 8:19.

16. Mahmood-Abadi HZ, Kayhani M, Rabi M, Mohammadi MR.A survey of knowledge and attitude of non-psychiatrists (medical specialists) treating major depression. Thrita Stud J MED Sci, 2012;1:30-3.

17. Chin SH, Balon R. Attitudes and perceptions toward depression and schizophrenia among residents in different medical specialties. Acad Psychiatry, 2006; 30:262-63.

18. Voinescu BI, Aurora S. Attitudes towards psychiatry. A survey of Romanian medical residents. Acad Psychiatry, 2010; 34:75-8.

19. Shen-Ing L, Ru-Band Lu, Ming-Been L. Nonpsychiatric physicians' knowledge, attitudes and behavior towards depression. $J$ Formos Med Assoc, 2008; 107:921-31.

20. Glasser M, Gravdal JA. Assessment and treatment of geriatric depression in primary care settings. Arch Fam Med, 1997; 6:433-38.

21. Schulze B. Stigma and mental health professionals. A review of the evidence on an intricate relationship. Int Rev Psychiatry, 2007; 19:137-55.

22. Morgan JF, Killoughery M. Hospital doctors' management of psychological problems Mayou \& Smith revisited. Br J Psychiatry, 2001; 182:153-57.

DOI: http://dx.doi.org/10.4314/ejhs.v28i6.12 